\title{
Conselhos de Saúde \\ e a Participação Social no Brasil: Matizes da Utopia ${ }^{1}$
}

I 1 Poliana Cardoso Martins, ${ }^{2}$ Rosangela Minardi Mitre Cotta, ${ }^{3}$ Fábio Farias Mendes, ${ }^{4}$ Sylvia do Carmo Castro Franceschinni, ${ }^{4}$ Silvia Eloiza Priore, ${ }^{1}$ Glauce Dias, ${ }^{5}$ Rodrigo Siqueira-Batista I

Resumo: Este artigo discute a construção social da participação da sociedade civil no Sistema Único de Saúde, tendo como reflexão inicial os avanços alcançados no plano legal, em contrapartida aos obstáculos observados no cotidiano da construção dos espaços de exercício da democracia; ou seja, a distância entre "o espírito e a letra da lei”. Visa a analisar o processo de criação dos conselhos de saúde no Brasil, descrevendo sua importância para uma efetiva participação da sociedade civil na tomada de decisão na área da saúde, refletindo sobre os matizes desta utopia; destaca os desafios encontrados e as possibilidades apresentadas para concretização desta ação; ressalta a possibilidade da presença ativa dos sujeitos na construção do processo democrático no SUS e abre a discussão sobre a necessidade de empoderamento e libertação da população. Por fim, discorre sobre a exclusão e marginalização de um substantivo contingente da população, colocando em questão não apenas a construção da cidadania no país, mas o próprio conceito de cidadania.

\footnotetext{
Palavras-chave: Participação social; conselho de saúde; cidadania.
}

\author{
${ }^{1}$ Mestre em Ciências da \\ Nutrição, Departamento de \\ Nutrição e Saúde, Universidade \\ Federal de Viçosa. \\ 2 Professora adjunta, \\ Departamento de Nutrição e \\ Saúde, Universidade Federal de \\ Viçosa; doutora em Saúde \\ Pública pela Universidade de \\ Valência, Espanha. Endereço \\ eletrônico: rmmitre@ufv.br. \\ ${ }^{3}$ Professor adjunto, \\ Departamento de Artes e \\ Humanidades, Universidade \\ Federal de Viçosa; doutor em \\ Ciência Política pelo IUPERJ. \\ ${ }^{4}$ Professora adjunta, \\ Departamento de Nutrição e \\ Saúde, Universidade Federal de \\ Viçosa; doutora em Ciências \\ Escola Paulista de Medicina, \\ Universidade de São Paulo. \\ ${ }^{5}$ Doutor em Ciências, Fundação \\ Oswaldo Cruz; professor titular, \\ Centro Universitário Serra dos \\ Órgãos (UNIFESO); professor \\ adjunto, Centro Federal de \\ Educação Tecnológica de \\ Química de Nilópolis (CEFET \\ Química de Nilópolis, RJ).
} Aprovado em: 26/07/2007. 


\section{Introdução}

Tomou-se como base para reflexão o texto constitucional de 1988, relacionado ao capítulo da seguridade social/saúde, a Leis Orgânicas da Saúde e a Resolução n ${ }^{\circ}$ 333, do Conselho Nacional e Saúde (CNS), que colocam em pauta na agenda nacional a participação e o controle social do sistema de saúde, abrindo, desta forma, espaço para o resgate da cidadania do povo brasileiro.

Esses textos representam um inquestionável avanço no plano legal, mas ainda encontram vários desafios para sua efetivação, dentre os quais se pode cita, a dificuldade de construção de uma consciência sanitária e de viabilização de uma mais efetiva participação e controle social, impossibilitando assim a materialização das conquistas almejadas (COTTA et al., 1998; BOSSI; MERCADO, 2004).

Neste sentido, a discussão sobre o processo de criação dos conselhos de saúde no Brasil e sua importância para a participação da sociedade civil na tomada de decisão é elemento primordial no processo de construção da cidadania, sendo ainda importante instrumento de controle social e mecanismo estratégico na garantia do direito à saúde, fundamentado nos princípios da democratização do poder decisório no Sistema Único de Saúde (SUS).

No conjunto das discussões, cada vez mais intensas, sobre os rumos técnicos e políticos do SUS, a questão da participação social tem merecido destaque (VALLA, 1998). Desde o movimento da reforma sanitária, a participação popular assumiu importante papel na saúde coletiva, onde os conselhos de saúde vêm convergindo como instâncias de ação política, para transformar e reconstruir, democraticamente, o espaço público e as relações entre a sociedade civil e o Estado (OLIVEIRA, 2004).

Esses conselhos são considerados uma estratégia institucional, que tem por finalidade não somente abrir as portas do setor saúde à participação da sociedade civil organizada, mas reforçar a dinâmica social, no sentido de sua organização em associações de interesse, facilitando a disseminação da cultura participativa própria de uma comunidade cívica, que encontra na justiça, na eqüidade, na solidariedade, na confiança e na tolerância seus princípios fundamentais (LABRA, 2005).

Alguns estudos têm demonstrado entraves para a efetiva participação da sociedade civil nos conselhos de saúde. A literatura sobre o tema indica que o funcionamento dos conselhos de saúde não é semelhante em todo o país, visto que muitas localidades apresentam inúmeras dificuldades para seu funcionamento (COTTA et al., 1998; LABRA, 2002; CORREIA, 2005; VAN STRALEN et al., 2006). 
Com base nas perspectivas aqui apresentadas, o presente trabalho tem como objetivo discutir os principais dilemas que estão hoje postos na questão da participação social no Brasil, descrevendo a importância dos conselhos de saúde para a efetiva participação da sociedade civil na tomada de decisão na área da saúde, refletindo sobre os matizes dessa utopia ${ }^{2}$ e destacando os desafios encontrados e as possibilidades apresentadas para uma efetiva participação social.

\section{Participação social no Brasil: considerações sobre o processo histórico}

A construção do projeto alternativo de reforma do sistema sanitário no Brasil tem seus antecedentes no final dos anos 1970, período em que a sociedade brasileira passava por um processo de transformação nas relações entre Estado e sociedade, desencadeada por duras críticas ao regime militar, sobretudo na área social, cobrando uma dívida social acumulada durante mais de uma década de repressão da voz da sociedade (PEGO; ALMEIDA, 2001; SIQUEIRA-BATISTA, 2006).

A luta pela democratização do país, e conseqüentemente da saúde, convergiu para um importante movimento nacional que reivindicou mudanças radicais no caótico, ineficiente e insuficiente sistema sanitário existente. O chamado Movimento da Reforma Sanitária levou à ampliação da organização popular e a emergência de novos atores sociais, produzindo e incrementando as demandas sociais sobre o Estado. Desencadeou um forte movimento pela universalização do acesso e reconhecimento da saúde como direito universal, cabendo ao Estado garanti-la à população (BRASIL, 2002), visando à ampliação dos direitos de cidadania a todos, priorizando a inclusão das camadas sociais marginalizadas no processo histórico de acumulação do capital, que tiveram suas liberdades de participação e organização suprimidas durante os anos de autoritarismo vividos no país (COTTA et al., 1998).

A Reforma Sanitária visava a produzir um novo conhecimento e práxis, que abarcasse as causas populares e que fosse capaz de materializar uma proposta alternativa de saúde, baseada no princípio de saúde como um direito de cidadania. De fato, o movimento lutava pela transformação social, advogando a constituição de sujeitos dotados de consciência social, conquistada através de sua consciência sanitária (PEGO; ALMEIDA, 2001).

Dentro deste contexto social e político, ocorre no ano de 1986, a VIII Conferência Nacional de Saúde, que se constituí como um marco na história da 
saúde no Brasil, reunindo pela primeira vez uma gama diversificada de representantes sociais de todo o país, resultando na ampla legitimação dos pressupostos político-ideológicos do Movimento da Reforma Sanitária. Nesta conferência foram definidos os princípios básicos sobre os quais o SUS deveria ser institucionalizado, servindo de subsídios para a aprovação do Capítulo Saúde na Constituição Federal de 1988.

A participação social foi pensada e vivida nesta conferência, a partir da inserção da população na determinação, acompanhamento e fiscalização das políticas de saúde, em todos os níveis do sistema de saúde (GUIZARDI et al., 2004). Nesse contexto, a Constituição da República Federativa do Brasil, promulgada em 1988, abre perspectivas para apoiar as açôes no domínio social, ou açôes na esfera pública que possam remeter à questão social. Prevê, dessa forma, a participação popular na gestão pública — seja ou não por via institucional —, prevalecendo, assim, a vontade da população sobre aquela de qualquer indivíduo ou grupo (BRASIL, 1988). Entendendo que no campo da saúde pública, a participação popular se faz de extrema importância, devido ao fato, de só ser possível avançar na qualidade dos serviços e ações de saúde com a participação efetiva da população, na medida em que seus atores se tornam capazes de apontar os problemas e as soluções relativas às suas reais demandas (ANDRADE; VAITSMAM, 2002).

O arcabouço jurídico-institucional da Constituição de 1988 é complementado pelas leis orgânicas da saúde (8.080 e 8.142). A Lei n. 8.080 regula as ações e serviços públicos e privados de saúde no que concerne a sua direção, gestão, competências e atribuições em cada nível de governo (BRASIL, 1990a). A Lei n. 8.142, vem para complementá-la em decorrência dos vetos efetuados, pelo então Presidente da República. Esta segunda lei estabelece e dispõe legalmente, entre outras questôes, sobre o controle social através da criação das Conferências de Saúde e dos Conselhos de Saúde abertos à participação de diferentes membros da sociedade civil, nas três esferas de governo (BRASIL, 1990b).

Diante dessa realidade, os conselhos de saúde são reconhecidos como resultado da revitalização da sociedade civil durante o processo de redemocratização do país e uma derivação direta das exigências em prol da saúde como um direito universal a ser garantido pelo Estado (LABRA, 2005). 
Os conselhos de saúde como espaços democráticos de participação social

Os Conselhos de Saúde podem ser entendidos como um espaço deliberativo da máquina político-institucional do SUS, sendo instrumento privilegiado para fazer valer os direitos dos cidadãos, rompendo com as tradicionais formas de gestão e possibilitando a ampliação dos espaços de decisão e ação do poder público. Estas instâncias impulsionam a constituição de esferas públicas democráticas, transformando-se também em potenciais capacitadores dos sujeitos sociais para processos participativos mais amplos de interlocução com o Estado (KRUGER, 2000).

A Lei n. 8.142/90 confere aos Conselhos de Saúde as atribuições de atuar na co-gestão do SUS nas três esferas de poder, interferindo na formulação de estratégias e no controle da execução das políticas de saúde, atribuições estas que são também do próprio Poder Executivo e do Poder Legislativo. Os conselhos devem ser criados por lei municipal, estadual ou federal com base na Lei $\mathrm{n}$. 8.142/90, destacando que, tanto no processo de criação como na reformulação do conselho, o poder público, com base nos princípios democráticos, deve acolher as demandas da população, consubstanciadas nas resoluções das conferências de saúde (BRASIL, 2003).

A composição dos conselhos deve se dar por representantes do governo, prestadores de serviços, profissionais da saúde e usuários. Este fato representa importante inovação no âmbito da organização do setor saúde brasileiro, com a particularidade de se situar na contramão da tradicional tendência clientelista e autoritária do Estado brasileiro. Aparece como um constructo institucional expressivo da imagem-objetivo de democracia em saúde, perseguida pelo Movimento da Reforma Sanitária (CARVALHO, 1995), apostando na construção de uma sociedade mais justa e livre, baseada no aprofundamento da democracia participativa como principal mecanismo para atingir a dignidade, a liberdade e a justiça social. O objetivo central da participação dos usuários neste espaço é viabilizar sua atuação nas deliberaçôes sobre as políticas e programas de saúde, exercendo o controle sobre os atos das autoridades locais destinadas a implementar as diretrizes decididas com o aval do próprio conselho (ASSIS; VILLA, 2003). 
De acordo com a Pesquisa de Informações Municipais, realizada em 2001 pelo Instituto Brasileiro de Geografia e Estatística (IBGE), 97,6\% dos municípios brasileiros têm instituídos os conselhos de saúde, sendo que em 98,7\% destes municípios, os conselhos realizaram reuniōes neste ano. A maioria dos municípios $(69,7 \%)$ informou que as reuniōes do conselho são "muito freqüentes", mas em $10,3 \%$ as reuniōes ocorrem de forma irregular, sendo esta situação mais comum nos municípios de pequeno porte. Essas informações indicam que embora a maioria dos conselhos municipais de saúde esteja em efetivo funcionamento, alguns ainda parecem não atuar como preconizado, podendo estar constituídos apenas para cumprir um dispositivo legal (IBGE, 2003).

Observa-se profusa ampliação destas arenas de deliberação e debate no Brasil, desde a implantação do SUS. Evidências empíricas comprovam que os conselhos enfrentam enormes problemas de funcionamento, principalmente na legitimação e eficácia dessas arenas. Esse paradoxo é compreensível e coerente com o descompasso que as democracias maduras - como nas democracias européias levaram mais de um século para equacioná-lo, uma vez que, por um lado, tem-se a pouca adesão dos governantes e, por outro, a disseminação ainda capilar desses valores no seio da sociedade (LABRA, 2005).

\section{Participação da sociedade: entraves e desafios para a sua viabilização}

Em uma sociedade democrática, a cidadania consiste no direito de as pessoas definirem as regras do jogo, contando com mecanismos que visem a garantir a efetividade desses direitos. A experiência histórica tem revelado que a participação cidadã na área da saúde se mostra de diversas formas: (1) participação como beneficiário, onde as pessoas são consideradas como simples beneficiárias da atenção à saúde; (2) participação como contribuição para a promoção da saúde, onde a participação ocorre por meio do apoio voluntário da população aos programas e projetos de desenvolvimento social; (3) participaçāo comunitária, que interpreta a participação como a organização da comunidade em grupos de apoio aos programas e projetos, no intuito de obter recursos, transmitir conhecimentos e capacitar a população para que se transforme em agente ativo de seu desenvolvimento; e, por fim, (4) uma visão mais complexa de participação em saúde que reconhece as pessoas como usuárias e cidadãs, às quais o sistema de saúde deve prestar conta de seu 
funcionamento, respeitando a cidadania e implementando distintos mecanismos de participação individual e coletivos, que permitam aos indivíduos exercerem controle sobre seus direitos de proteção à saúde (CELEDÓN; NOÉ, 2001).

No Brasil, apesar dos esforços para consolidar essa visão mais moderna e complexa de participação, nota-se que o quadro de reordenação social e política ainda não experimentou um progresso seqüencial dos direitos civis, políticos e sociais, apresentando na realidade, a construção lenta da cidadania como valor coletivo. A realidade vivida remete a uma versão híbrida e frágil dos direitos civis, marcada pela escravidão e pela instabilidade política, não contribuindo para o amadurecimento da cidadania plena. O perfil vigente de cidadania no Brasil aponta para a existência de grande parte da população à margem da comunidade política, o que certamente tem implicações em nosso padrão de intervenção pública e integração social (CARVALHO, 2004).

Analisando de forma global os acontecimentos da década de 1990, observa-se que esta foi marcada por um refluxo dos movimentos populares e sindicais após a efervescência política dos anos 1980. Destaca-se que nesse período ocorreu grande submissão do país aos agentes econômicos internacionais, com a inserção subordinada na globalização mundial, aumentando o peso do "voto de mercado" no destino das políticas econômicas e sociais (CORREIA, 2005).

Ao analisarmos a situação do Brasil dentro desta perspectiva, observa-se que a consolidação da Constituição Federal de 1988 como um símbolo da vontade dos legisladores, em conduzir a nação à plena democracia, ainda não simbolizou mudanças nas crenças e comportamentos das elites dominantes, das instituições e das organizações da sociedade civil que traduzam uma renovação da cultura política e cívica do país (LABRA, 2005).

Inúmeras evidências têm demonstrado que apenas a existência formal dos espaços de controle social não assegura a participação política da sociedade. Os conselhos de saúde, em maior ou menor grau, apresentam uma série de problemas que compromete sua eficácia (COTTA et al., 1998; LABRA, 2002 e 2005; WENDHAUSEN; CAPONI, 2002; GUIZARDI et al., 2004).

Uns dos problemas mais freqüentes e difíceis de serem solucionados na prática estão relacionados a composição, representação e representatividade do conselho. Com freqüência, a composição do conselho não respeita os princípios da paridade, e os critérios de escolha de seus membros são obscuros. Observa-se, em muitos 
casos, ingerências políticas na escolha de conselheiros, principalmente daqueles que representam os interesses dos usuários e, desta forma, estes acabam por não representar verdadeiramente os interesses dos cidadãos comuns. Em muitos casos, mesmo que a presença quantitativa dos representantes da população seja assegurada pelo requisito jurídico da paridade, não se observa correspondência direta da capacidade de intervenção desse grupo (LABRA, 2002 e 2005; WENDHAUSEN; CAPONI, 2002; GUIZARDI et al. 2004; GUIZARDI; PINHEIRO, 2006).

Labra (2005) relata a ocorrência de casos em que um mesmo conselheiro representa segmentos diferentes da sociedade (por exemplo: usuários e prestadores), ou é um político em cargo eletivo (um vereador), ou é indicado pelo prefeito, por entidades alheias ao conselho ou por agremiaçôes desconhecidas da comunidade. Outro fato importante a ser destacado é a coibição exercida por alguns membros pertencentes à elite política local, à livre expressão do demais conselheiros.

Este fenômeno de representação dos conselheiros pode ser pensado a partir das reflexões de Norberto Bobbio (1992), que discute a questão da democracia e da participação dentro do âmbito da própria sociedade capitalista contemporânea. Aqui a forma de representação no conselho deve ser interpretada de acordo com os pressupostos da democracia representativa, e não de uma democracia direta, que segundo esse autor só se dá pela forma de um referendo popular. Assim, a democracia se estende da esfera das relações políticas, na qual o indivíduo é entendido em seu papel de cidadão na clássica equação: um indivíduo = um voto, para a esfera das relações sociais, em que o indivíduo é considerado na variedade de seus papéis e de seu respectivo status na sociedade. Este processo de democracia não implica uma passagem da democracia representativa para uma democracia direta, e sim, da democracia política para a democracia social, onde o ângulo visual se desloca do Estado para a sociedade civil.

Outra questão que compromete a atuação dos conselhos é o fato de estes serem pouco conhecidos pela população e a não-divulgação das atividades e das iniciativas relacionadas aos mesmos para a comunidade. Esta situação leva a um desconhecimento da população sobre os objetivos, as funções e a atuação do conselho, representando como resultado final uma baixa adesão desta nos processos decisórios locais (LABRA, 2005). Assim, pode-se ressaltar que o conselho pode até ser uma instituição muito valorizada por aqueles que dele participam, mas é desconhecido pela grande parte dos cidadãos. Tal fato é confirmado por Navarrete et al. (2003), 
que observaram que a maioria dos usuários do SUS entrevistados em dois municípios do nordeste do Brasil relatou a utilização dos serviços de saúde como a principal forma de participação social em saúde.

A falta de conhecimento sobre a atuação dos conselhos não é detectada apenas entre os usuários do SUS. Nota-se que os próprios gestores e membros dos conselhos apresentam um conhecimento insatisfatório sobre o papel e a importância do mesmo. Essa realidade tem sido apontada por diversos autores como fator limitante à implantação do princípio da participação social em diversos municípios brasileiros, uma vez que, no exercício de suas funçóes, os conselhos de saúde demandam dos cidadãos uma crescente capacidade de atuar politicamente, promover negociações e acordos, resolver conflitos, fiscalizar e estabelecer prioridades no campo da saúde (CORREIA, 2005).

Entretanto, esta situação de desconhecimento de alguns membros tem sido muitas vezes utilizada por alguns gestores e autoridades públicas como pretexto para reforçar a imagem que os representantes dos usuários são técnica e socialmente despreparados para perceberem com clareza a lógica de funcionamento e as necessidades do sistema de saúde. Justificam, assim, a atuação dos gestores no controle das atividades do conselho, como a definição dos membros, a determinação das agendas do conselho, definindo quais assuntos são considerados pertinentes e relevantes, dentre outras. Como conseqüência, os conselhos acabam sendo interpretados como instâncias meramente homologatórias das decisões do gestor, atendendo muito mais a uma formalidade legal do sistema do que propondo formas de alterações nas relações de poder entre sociedade e Estado (OLIVEIRA; GUSMÃO, 2004).

Outro aspecto importante a se destacar é que, apesar de o SUS apresentar em sua base legal princípios e diretrizes que contemplam a universalidade, eqüidade, integralidade, descentralização e participação social, observa-se na prática que este tem sido alvo das reformas neoliberais, que acabaram por representar um grande retrocesso nas políticas sociais conquistadas legalmente (CORREIA, 2005). $\mathrm{Na}$ verdade assiste-se, no Brasil, uma "universalização excludente", ou seja, juntamente com a universalização do acesso aos serviços de saúde a toda população, independentemente da sua posição no mercado formal de trabalho, ocorreu a precarização desses serviços, resultando na exclusão das camadas mais bem remuneradas da sociedade para o sistema privado (FAVERET; OLIVEIRA, 1990). 
Esta "saída" do sistema, de um grupo social que mais se preocupa com a qualidade do serviço e que, conseqüentemente, poderia se portar de forma mais ativa e criativa como a voz da sociedade, tem representado um custo ao processo democrático, reduzindo o poder de negociação e de influência da sociedade na organização dos serviços públicos (HIRSCHMAN, 1973). Partindo do pressuposto de que as demandas sociais por infra-estrutura e serviços acabam por politizar os atores sociais, levando-os a conquistar direitos e desenvolver ações relacionadas à cidadania, observase no Brasil que as desigualdades sociais existentes e a precariedade dos serviços públicos, considerados como serviços para pobres, têm levado à criação de categorias de cidadãos. Desta forma, faz-se necessário o entendimento de cidadania não apenas como conquista material e social, mas como a construção de uma identidade que se opõem à idéia de exclusão - ou de uma sociedade com dois tipos de cidadãos (DALARI et al., 1996) -, ainda que tal entendimento possa conter substantivos problemas teóricos, como será discutido adiante.

\section{Possibilidades para a participação: abrindo espaço para a discussão}

O reconhecimento que apenas a exigência legal para o controle social não têm se mostrado suficiente para sua legitimação no país levou à proposição de algumas táticas de intervenção que visem à efetivação deste princípio constitucional (COTTA et al., 1998; VAN SATRALEN et al., 2006). As estratégias de capacitação dos conselheiros, com o intuito de fortalecer a dinâmica interna dos conselhos de saúde e sua relação com a sociedade, têm sido apontadas como um caminho para essa mudança das práticas existentes. Com a institucionalização dos conselhos de saúde, surge a necessidade de novos atores sociais, com a função de atuar na formulação de estratégias e no controle da execução da política de saúde na instância correspondente, inclusive nos aspectos econômicos e financeiros, e essa responsabilidade requer destes atores acesso a informaçóes e conhecimentos necessários a tais funções (CORREIA, 2005).

Um estudo que visava a avaliar o impacto do processo de capacitação de conselheiros sobre o desempenho do conselho observou que os conselheiros capacitados apresentam média mais elevada de intervenções nas reuniões e de articulação com sua base, do que os conselheiros não capacitados (CORREIA, 2005). Observa-se, em alguns municípios, que a estratégia utilizada para reverter 
essa situação, em função da complexidade da dinâmica desse espaço, é a escolha dos membros do conselho marcada pela especialização e elitização dos escolhidos. Isso tende a concentrar cada vez mais o contingente de usuários que efetivamente participam dessas dinâmicas (GUIZARDI et al, 2005), onde muitas vezes há, como representantes dos usuários no conselho, atores sociais que não se identificam com a realidade vivida pela maioria da população.

Deve-se destacar também a necessidade de democratizar a informação, uma vez que o exercício do controle e a participação social ocorrem em espaços públicos, o que demanda visibilidade e compartilhamento do que é público. Tudo o que vem a público pode ser visto, ouvido e comentado por todos, assim, a atuação dos conselhos só pode ocorrer em determinado campo cultural ou político, onde existam informações disponíveis e sejam reconhecidas as capacidade dos atores que ali atuam de interpretar e atribuir novos sentidos a elas (OLIVEIRA; GUSMÃO, 2004).

Segundo Freire (1996, p. 31-32),

reconhecer que, precisamente porque nos tornamos seres capazes de observar, de comparar, de avaliar, de escolher, de decidir, de intervir, de romper, de optar, nos faz seres éticos [...] capazes de lutar contra os fatalismos quietistas que terminam por absorver as transgressōes em lugar de condená-las.

É necessário, então, contar com a presença ativa dos sujeitos na construção, admiração e re-admiração do mundo, podendo assim mudar a realidade do SUS. Neste sentido, destaca-se a importância estratégica do conceito de empoderamento (empowerment), definido como o processo através do qual pessoas ou comunidades adquirem maior controle sobre as decisões e ações que afetam sua saúde (WHO, 1998), ampliando as possibilidades de controle dos aspectos significativos relacionados à sua própria existência (SEN, 2001 e 2002). Esse conceito está em íntima comunhão com a idéia de libertação trabalhada por Paulo Freire (FREIRE, 1996 e 2004). De fato, o economista Amartya Kumar Sen caracteriza como empoderamento aquilo que o educador Paulo Freire chama de libertação daqueles cidadãos que logram sua inclusão social. Entretanto, este último traz uma concepção mais ampla e generosa do cidadão que se liberta da situação de exclusão por meio da educação (GARRAFA, 2005).

O empoderamento/libertação pode ser interpretado como uma forma de redistribuir o poder que se encontra desigualmente distribuído na sociedade (CARVALHO, 2004). Entretanto, para promover tal redistribuição, é necessário 
haver participação política com o intuito de democratizar o poder, o que significa subordinar o funcionamento do Estado à sociedade, mas sem o intuito de fortalecer a ação coletiva contra as estruturas de poder do Estado. Deve-se implantar um método de construção de consenso que exige negociação e concentração social, requerendo a participação dos cidadãos no processo de tomada de decisão e de controle das ações (STOTZ; ARAÚJO, 2004).

\section{Ponderações finais}

Apesar do imenso avanço do engajamento da sociedade civil em arenas de formulação e deliberação das políticas públicas, ainda se está longe de alcançar a plenitude da democracia republicana e pluralista moderna. Este contexto é uma firme justificativa para estudar a fundo a dinâmica e o funcionamento dos conselhos de saúde, uma vez que estes constituem uma inovação política institucional e cultural na consolidação do SUS, especialmente para se compreender a natureza das dificuldades a serem enfrentadas, das quais se destacam aquelas relativas à desigualdade e à exclusão de atores sociais importantes nesse jogo político.

De fato, a construção de uma participação social mais ampla na tomada de decisão sobre os diversos aspectos da vida pública ainda esbarra na exclusão e marginalização de um substantivo contingente da população. A existência de "fileiras" de pessoas marginalizadas coloca em questão não apenas a construção da cidadania no país, mas o próprio conceito de cidadania, o qual, já no seu nascimento na cultura helênica, traz a marca da exclusão - de fato, um percentual pequeno da população das póleis (cidades-estados) pertencia a "classe" dos cidadãos. Ademais, Jacques Derrida demonstra que o conceito de cidadania tornou-se suspeito por ser tão somente abstrato, em decorrência do número de excluídos, não de jure, mas de facto (DERRIDA, 2001; SCHRAMM, 2004).

Tal é a situação no Brasil, país no qual, apesar do avanço legal para a fundamentação dos direitos sociais, observa-se sua negação à maioria da população, situação matizada pela "doação" de cidadania pelo Estado, da forma que este estipula e que melhor lhe convém. De acordo com Marilena Chauí (1986), a cidadania no Brasil tem sido historicamente marcada pela concessão regulada e periódica da classe dominante às demais classes sociais, sendo-lhes retirada quando os dominantes assim o decidirem. 
Este paradoxo acerca da cidadania se inscreve nos debates em torno da democracia, como já visto na menção à passagem da democracia política para a democracia social, em concordância com o pensamento de Norberto Bobbio. É possível pensar, uma vez mais com Derrida, em uma transformação, ainda mais radical, em direção à démocratie à venir (democracia por vir), na qual a categoria de cidadania seria substituída pela hospitalidade incondicional, ou seja, uma "solidariedade mundial que não seja simplesmente uma solidariedade entre os cidadãos, mas que poderia ser também uma solidariedade dos seres vivos, não constituindo justamente, em primeiro lugar, uma política dos cidadãos" (DERRIDA, 2001). Neste mesmo sentido, Cortina (1999, p. 97), destaca:

a necessidade das sociedades pós-industriais, de gerar em cada um de seus membros um tipo de identidade na qual se reconheçam e que se façam sentir-se pertencentes a elas, porque este tipo de sociedades adoece claramente de um déficit de adesão por parte dos cidadãos ao conjunto da comunidade, e sem essa adesão é impossível responder conjuntamente aos desafios que a todos se impõem [tradução nossa].

Por tudo isso, segue sendo necessário que se reclame para todos os cidadãos a proteção dos direitos econômicos, sociais, políticos e culturais e, sobretudo, que se proponha como tarefa histórica conseguir que estes direitos sejam parte integrante da vida de todas as pessoas. Discutir a exclusão social "típica” da cidadania parece ser um dos elementos cruciais para a ampliação dos debates sobre a atuação dos conselhos de saúde. A colocação deste tema pode ter implicações decisivas nas atitudes dos atores envolvidos, concorrendo, por exemplo, para minimizar os riscos de utilização premeditada - e indevida - do controle social por gestores e políticos, com a finalidade última de puro e simples exercício de poder.

Um dos grandes desafios porvir, utilizando a concepção de democracia de Derrida (2001), é a construção de uma gestão transparente e com ampla participação social, na qual as prioridades, definidas em gestôes colegiadas, sejam realmente orientadas para a resolução dos problemas de saúde da população, permitindo que seus cidadãoshóspedes possam ser incondicionalmente acolhidos em seus mais legítimos anseios. A partir daí, tanto os setores progressistas como os conservadores passam a exigir a transformação da cidadania passiva em ativa, transitando do tempo dos direitos às responsabilidades. Neste sentido, o desafio que se impõe é a transformação de uma cidadania acostumada a exigir, em uma cidadania acostumada a participar de projetos comuns, assumindo as responsabilidades dos diversos atores sociais. 


\section{Referências}

ANDRADE, G. R. B.; VAITSMAN, J. Apoio social e redes: conectando solidariedade e saúde. Ciência e Saúde Coletiva, Rio de Janeiro, v. 7, n. 4, p. 925-934, 2002.

ASSIS, M.M.A.; VILLA, T. C. S. O controle social e a democratização da informação: um processo em construção. Rev. Latino-Am Enfermagem, Ribeirão Preto, v. 11, n. 3, p. 376-82, 2003.

BOBBIO, N. O futuro da democracia: as regras do jogo. Rio de Janeiro: Paz e Terra, 1992. 128p.

BOSSI, M. L. M.; MERCADO, F. M. Pesquisa qualitativa de serviços de saúde. Petrópolis: Vozes, 2004. 607p.

BRASIL. Senado Federal. Constituição Federal. Brasília: Senado Federal, 1988.

BRASIL. Lei no 8.080, de 19 de setembro de 1990. Dispõe sobre as condições para a promoção, proteção e recuperação da saúde, a organização e o funcionamento dos serviços correspondentes e dá outras providências. Diário Oficial [da] República Federativa do Brasil, Brasília, DF, v. 128, n. 182, p. 18.055-18.055, 20 set. 1990. Seção I, pt. 1.

. Lei no 8142 , de 28 de dezembro de 1990. Dispõe sobre a participação da comunidade na gestão do Sistema Único de Saúde (SUS) e sobre as transferências intergovernamentais de recursos financeiros na área da saúde e dá outras providências. Diário Oficial [da] República Federativa do Brasil, Brasília, DF, 31 dez. 1990.

CARVALHO, A. I. Conselhos de saúde no Brasil: participação cidadã e controle social. Rio de Janeiro: FASE/IBAM, 1995. 136p.

CARVALHO, S. R. Os múltiplos sentidos da categoria "empowerment" no projeto de promoção da saúde. Cad. Saúde Pública, Rio de Janeiro, v. 20, n. 4, p. 1088-1095, 2004.

CELEDÓN, C.; NOÉ, M. Reformas del sector de la salud y participación social. Rev Panam Salud Publica/Pan Am J Public Health, Washington, v. 8, n.1/2, p. 99-104, 2001.

CHAUÍ, M. Conformismo e resistência: aspectos da cultura popular no Brasil. São Paulo: Brasiliense, 1986. 180p.

CONSELHO NACIONAL DE SAÚDE (Brasil) A prática do controle social: conselhos de saúde e financiamento do SUS. Brasília, 2002.60p.

. Resolução no 333, de 04 de novembro de 2003. Aprova as diretrizes para criação, reformulação, estruturação e funcionamento dos Conselhos de Saúde. Diário Oficial da União; Poder Executivo, Brasília, DF, n. 236, 4 dez. 2003. Seção 1, p. 57-8.

CORREIA, M. V. C. Desafios para o controle social: subsídios para a capacitação de conselheiros de saúde. Rio de Janeiro, FIOCRUZ, 2005. 208p.

CORTINA, A. Ciudadanos del mundo: hacia uma teoria de la ciudadanía. Madrid: Alianza, 1999. 264p. 
COTTA, R. M. M.; MENDES, F. F.; MUNIZ, J. N. Descentralização das políticas públicas de saúde: do imaginário ao real. Viçosa: Ed. UFV/CEBES, 1998. 148p.

DALARRI, S. G.; ADORNO, R. C. F.; FARIA, M. M. et al. O direito à saúde na visão de um conselho municipal de saúde. Cad. Saúde Pública, Rio de Janeiro, v. 12, n. 4, p. 531-540, out./dez. 1996.

DERRIDA, J. A solidariedade dos seres vivos: entrevista com Evandro Nascimento. Folha de S. Paulo, São Paulo, 27 de maio de 2001, Suplemento Mais!, p. 12-16.

FAVERET FILHO, P.; OLIVEIRA, P. J. A universalização excludente: reflexões sobre as tendências do sistema de saúde. Dados - Revista de Ciências Sociais, Rio de Janeiro, v. 33, n. 2, p. 257-283, 1990.

FREIRE, P. Pedagogia da autonomia: saberes necessários à prática educativa. 35. ed. São Paulo: Paz e Terra, 1996. 148p.

. Pedagogia do oprimido. 38. ed. São Paulo: Paz e Terra, 2004. 245p.

GARRAFA, V. A inclusão social no contexto da bioética. In: ANVISA. Seminário Mensal julho/ 2005, Brasília; CONGRESSO NACIONAL DA REDE UNIDA, 6., 2005, Belo Horizonte. Painel "Bioética: inclusão e justiça social".

GUIZARDI, F. L.; PINHEIRO, R. Dilemas culturais, sociais e políticos da participação dos movimentos sociais nos Conselhos de Saúde. Ciênc. Saúde Coletiva, Rio de Janeiro, v. 11, n. 3, p. 797-805, set. 2006.

GUIZARDI, F. L.; PINHEIRO, R.; MACHADO, F. R. S. Vozes da participação: espaços, resistências e o poder da informação. In: PINHEIRO, R.; MATTOS, R. A. (Org.). Construção social da demanda: direito à saúde, trabalho em equipe, participação e espaços públicos. Rio de Janeiro: CEPESC/UERJ: ABRASCO, 2005. p.225-238.

GUIZARDI, F. L.; PINHEIRO, R.; MATTOS, R. A.; SANTANA, A. D.; MATTA, G.; GOMES, M. C. P. A. Participação da comunidade em espaços públicos: uma análise das Conferências Nacionais de Saúde. Physis: Revista de Saúde Coletiva, Rio de Janeiro, v. 1, n. 14, p. 15-39, 2004.

HIRSCHMAN, A. Saída voz e lealdade. São Paulo: Perspectivas, 1973. 159p.

IBGE. Pesquisa de informaçôes básicas municipais: perfil dos municípios brasileiros. Gestão Pública, 2001. Rio de Janeiro, 2003.

KRUGER, T. R. O desconhecimento da reforma sanitária e da legislação do SUS na prática do conselho de saúde. Planejamento e Políticas Públicas-IPEA, n. 22, p. 119-144, 2000.

LABRA, M. E. Capital social y consejos de salud en Brasil: um circulo virtuoso? Cad. Saúde Pública, Rio de Janeiro, n. 18, p. 47-55, 2002.

. Conselhos de Saúde: dilemas, avanços e desafios. In: LIMA, N. T (Org.). Saúde e Democracia. Rio de Janeiro: Fiocruz, 2005. p. 353-384. 
NAVARRETE, M. V.; SILVA, M. R. F.; CAMPOS, E. S. et al. Visión de los diferentes agentes sociales sobre la participación social en el sistema de salud en el nordeste de Brasil: una aproximación cualitativa. Rev. Esp. Salud Pública, Madri, v. 76, n. 5, p. 585-594, 2003.

OLIVEIRA, J. B.; GUSMÃO, S. C. A experiência de saúde da família no estímulo à participação social no município de Vitória da Conquista - BA. In: SECLEN-PALACIN, J. A.; FERNANDES, A. S. Experiências e desafios da atenção básica e saúde familiar: caso Brasil. Brasília: Organização PanAmericana da Saúde, 2004.

OLIVEIRA, V. C. Comunicação, informação e participação popular nos Conselhos de Saúde. Saúde e Sociedade, São Paulo, v. 13, n. 2, p. 56-69, 2004.

PEGO, R. A.; ALMEIDA, C. Teoria y pratica de las reformas en los sistemas de salud: los casos de Brasil y México. Cad. de Saúde Pública, Rio de Janeiro, v. 17, n. 1, p. 89-97, 2001.

SANTOS, B. S. Pela mão de Alice: o social e o político na pós-modernidade. 10. ed. São Paulo: Cortez, 2005.350p.

SCHRAMM, F. R. A moralidade da prática de pesquisa nas ciências sociais: aspectos epistemológicos e bioéticos. Ciênc. Saúde Coletiva, Rio de Janeiro, v. 9, n. 3, p. 773-784, set. 2004.

SEN, A. Desigualdade reexaminada. Rio de Janeiro: Record, 2001.300p.

. Por qué la equidade en salud? Pan American Journal of Public Health, Washington, v. 11, n. 5-6, p. 302-309, 2002.

SIQUEIRA-BATISTA, R. Miséria. 3. ed. Rio de Janeiro: Litteris, 2006.

STOTZ, E. M.; ARAÚJO, J. W. G. Promoção da saúde e cultura política: a reconstrução do consenso. Saúde e Sociedade, São Paulo, v. 13, n. 2, p. 5-19, maio/ago. 2004.

VALLA, V. V. Sobre a participação popular: uma questão de perspectiva. Cad. de Saúde Pública; Rio de Janeiro, v. 14, supl. 2, p. 7-18, 1998.

VAN STRALEN, C. J. et al. Conselhos de Saúde: efetividade do controle social em municípios de Goiás e Mato Grosso do Sul. Ciênc. Saúde Coletiva, Rio de Janeiro, v. 11, n. 3, p. 621-632, set. 2006.

\section{Notas}

${ }^{1}$ Este estudo faz parte da dissertação intitulada Controle social no Sistema Único de Saúde: análise da participação social e do empoderamento da população no município de Teixeiras, MG, defendida pela primeira autora deste artigo, sob orientação da segunda, na Universidade Federal de Viçosa. O projeto "Consolidação do Sistema Único de Saúde: A Estratégia de Saúde da Família enquanto instrumento de reorganização do sistema de saúde local e estímulo à participação social”, que originou a dissertação, foi financiado pela FAPEMIG EDT - Processo n.075/05 - 2005.

${ }^{2} \mathrm{O}$ conceito de utopia aqui descrito é entendido como a exploração de novas possibilidades e vontades humanas, por via da oposição da imaginação à necessidade do que existe, só porque existe em nome de algo radicalmente melhor, que a humanidade tem direito de desejar e lutar (SANTOS, 2005). 


\section{Abstract}

\section{Health Councils and Social Participation in} Brazil: Shades of an Utopia

This article discusses the social construction of the participation of civil society in the Unified Health System, and initially reflects on the progress in the legal area, against the daily obstacles in the construction of spaces to practice democracy; in other words, the distance between "the spirit and the letter of the law". It focuses on the analysis of the process of creation of health councils in Brazil, describing its importance for an effective participation of the civil society in decision-making in the health area, thinking over the shades of this utopia; it points out the challenges and possibilities for an effective social participation; it emphasizes the possibility of the active presence of subjects in the construction of the democratic process in the SUS and starts the discussion on the need to empower and to release the population. Finally it discusses the exclusion and marginalization of great part of the population, considering not only the construction of citizenship in Brazil, but also the concept of citizenship itself.

> Key words: social participation: Health Council; citizenship. 